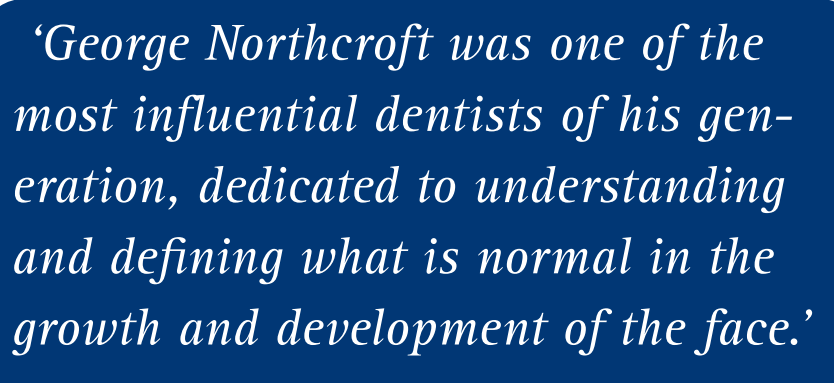

\title{
That great palace of truth
}

\author{
This December sees the 100th anniversary of the formation of the British Society for \\ the Study of Orthodontics, founded by George Northcroft and now subsumed into the \\ British Orthodontic Society. This article takes a brief look at Northcroft and his legacy, \\ part of which will be on display in the BDA Museum between May and July this year to \\ mark the centenary of the society Northcroft founded.
}

Imagine being a child and lying on the kitchen table with a drinking straw up each nostril. Your eyebrows are greased and plaster is poured onto your face. Throughout this procedure - the making of a facemask - you have to keep absolutely still in order for the mask to be accurately constructed. It is hard to imagine any child happily tolerating the experience more than once, but for one young man growing up early in the twentieth century this was routinely carried out by his father. Twelve masks were made, each one on the young William's birthday, between the ages of seven and twenty-one.

George Northcroft (1869-1943) was one of the most influential dentists of his generation and was dedicated to understanding and defining what is normal in the growth and development of the face. Without an understanding of normal growth and development, Northcroft said, it would be impossible to understand the aetiology of malocclusion.

The collection of facemasks of the young William Northcroft now represents the oldest 3D growth study in the world and is an important part of the
British Orthodontic Society's nascent museum. Other valuable items include the letter George Northcroft wrote inviting a few like-minded dentists to a meeting to discuss a society for orthodontia. This was how the British Society for the Study of Orthodontics (BSSO) came to be formed on December 5th 1907. To mark this centenary, some pieces from the British Orthodontic Society (BOS) collection will be on display in the museum of the British Dental Association between May and July.

George Northcroft qualified both in America, at the University of Michigan (1890) and then in England at the London School of Dental Surgery (1892), later to become the Royal Dental Hospital. It was unusual, if not unique, for a dentist to qualify in America first and it was there that his interest in orthodontics was stimulated. Edward Angle, widely acknowledged as the father of modern orthodontics, was advocating the formation of the orthodontic specialty on the West coast but on the East coast it was viewed as part of dentistry.

Northcroft was one of the founders of the London Hospital Dental School and

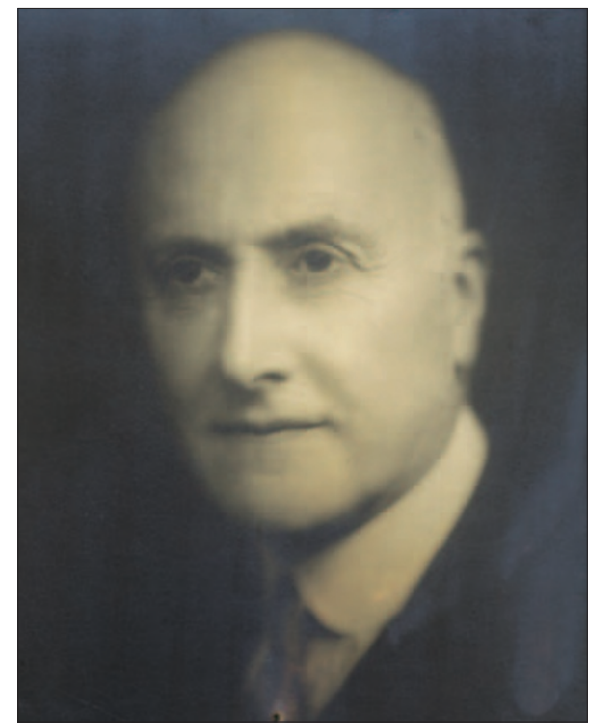

George Northcroft as BDA President, 1932

worked there for many years, also playing an important role in the negotiations that led to the Dental Act of 1921 which made dentistry a profession. He was twice President of the BDA and he was awarded the OBE. He also served as president of the European Orthodontic Society. 


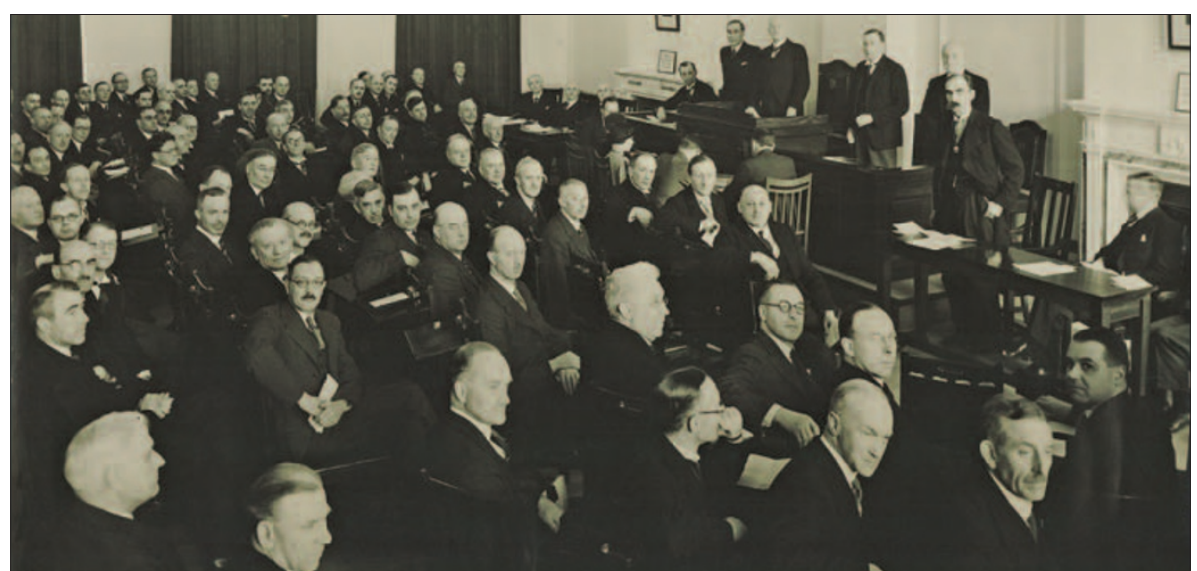

Northcroft preparing to present his research to BDA members on the occasion of the opening of the Hill Street Headquarters in 1935

For much of his working life his practice was in Harley Street, where members of the aristocracy and even royalty from throughout Europe consulted him. So esteemed was he, that when it was decided in 1935 to open up the urn thought to contain the bodies of the two Princes in the tower, the urn was brought to his practice. Together with Professor Wright, Professor of Anatomy at the London Hospital, he X-rayed the bones and confirmed that they belonged to two boys who were the same age as the princes were when they died.

The Northcroft legacy, which will be celebrated this year as part of the centenary of the BSSO, is immense (the BSSO, along with a number of other orthodontic organisations, was subsumed into BOS thirteen years ago). But this is not just a story of one man's achievements. Many have contributed in a variety of ways. Every year, the British Orthodontic Society's conference features the Northcroft Memorial Lecture, delivered by an outstanding orthodontist. In 1983 it was given by Professor Jim Moss and the subject was Northcroft himself (Moss J P. Northcroft revisited. Br J Orthod 1989; 16: 155-167). It is partly thanks to Jim that Northcroft's work on understanding the growth and development of the face has been perpetuated. This was through the development of laser scanning by Jim Moss and Alf Linney, working at University CollegeHospital, building on the foundations laid by Northcroft. Jim even went to meet William Northcroft, then aged 72, and took a further mask - this time from alginate - and a laser scan. The adult William confided that he had found the mask construction process very hot. One year he incurred his father's anger by chewing something and this caused a fracture in the plaster. This particular mask is slightly different from the others.

For many years the Curator of the BOS

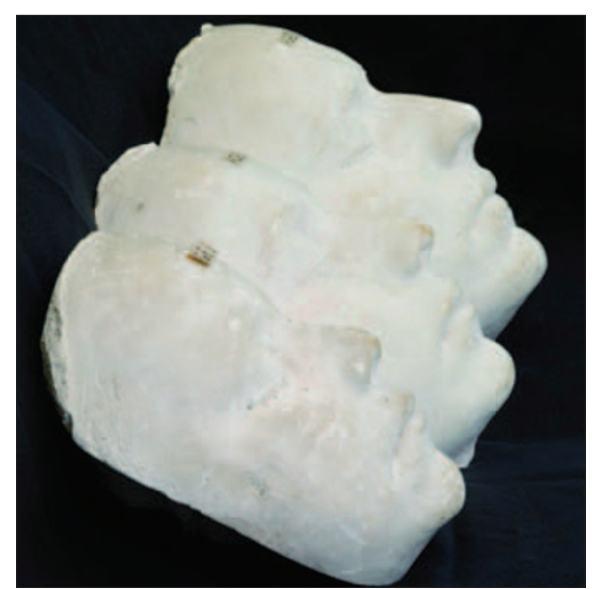

Some of the plaster facemasks Northcroft made of his son William as he grew

Museum, Jim Moss rescued the collection when it had no home. He made sure that it was safe in a variety of resting places - latterly the Royal London Hospital - until BOS finally had offices of its own. Now, with the support of the BDA Curator, Rachel Bairsto, and leading members of BOS including Chairman Iain Hathorn, this orthodontic archive is finally safe and in development.

How pleased George Northcroft would be! He would have approved especially of the combined efforts of BDA and BOS on an exhibition in the centenary year of BSSO. Northcroft tried through his work, he said of himself, to contribute 'something, however little, towards constructing that great palace of truth, in the building of which all scientists are collaborating.' How inspiring to think that one century later, although there are many different branches of dentistry and many places in which it is practiced and studied, so many members of the profession are contributing to the great palace of truth to which George Northcroft personally contributed so much.

Caroline Holland 